\title{
The effects of partial replacement of cement in cement mortar and brick by Microwave Incinerated Rice Husk Ash (MIRHA)
}

\author{
S. Wan, K. Vallyutham, M. S. Liew \& N. S. Potty \\ Civil Engineering Department, \\ Universiti Teknologi PETRONAS, Malaysia
}

\begin{abstract}
The demand for high quality sustainable materials has increased and encouraged the researchers in building technology to find new alternatives. Rice husk generated from the rice production poses a major problem of disposal especially when open burning is no longer permitted due to the environmental issues. The use of pozzolanic materials is being investigated to reduce the carbon dioxide emitted per tonne of concrete produced and utilized. This study investigates the potential of using Microwave Incinerated Rice Husk Ash (MIRHA) in mortar mixes made of Ordinary Portland Cement (OPC). The MIRHA was obtained by burning rice husk at controlled temperature using microwave incinerator. In the experimental study on compressive strength of cement mortar the water-binder ratio was kept constant at 0.5 . Control mortar without any replacement of cement and also mortar with $5 \%, 10 \%, 15 \%, 20 \%$ and $25 \%$ of OPC replaced by MIRHA were studied with different binder-sand ratio of 1:3, 1:4. 1:5 and 1:6. The compressive tests were conducted for the samples at 7 and 28 days. The result has revealed that, the MIRHA could be used in cement mortar due to its refined microstructures. In addition to that, the compressive test results were compared with three different standards: ASTM, MS and BS for bricks manufacturing. The results show the potential of using MIRHA in cement brick production. Amongst the cement replacement mixes, $20 \%$ MIRHA has shown highest compressive strength.
\end{abstract}

Keywords: Microwave Incinerated Rice Husk Ash, mortar, brick, cement replacement material. 


\section{Introduction}

Malaysia is one of the major rice producing countries with approximately $3.21 \%$ of total land in peninsular Malaysia under rice cultivation. On average, paddy production in Malaysia is about 2 million tonnes per year [1]. The rice husk generated from rice production has posed a major problem of disposal especially when open burning is no longer permitted due to environmental issues. Rice Husk Ash (RHA) has high amorphous silica content $(85 \%-90 \%)$ which can enhance the quality of mortar through the formation of calcium silicate [2].

The cement industry contributes $5 \%$ of global $\mathrm{CO}_{2}$ emission. The cement sustainability initiative progress report shows that of the total emissions from the cement industry, $40 \%$ occur during combustion and $60 \%$ during calcinations from the cement manufacturing process [3]. The intense consumption of concrete and brick in construction leads to a higher usage of cement and thereby higher emission of $\mathrm{CO}_{2}$.

Due to its pozzolanic effect, RHA is being used to partially replace Ordinary Portland Cement (OPC). When rice husks are burnt using a microwave incinerator to obtain MIRHA, they have enhanced silica content. MIRHA is an amorphous material that gives a positive effect to mortar as a binder in concrete as well as an option to reduce Portland cement consumption in the construction material [1]. This research intended to investigate the effect of partial replacement of cement with MIRHA in mortar and brick.

\section{Replacement of cement with MIRHA in bricks}

The research into the use of agriculture waste in construction material has made huge progress. Disposal of agriculture waste has posed an environmental problem since it possessed rough and abrasive surfaces which have high resistance to natural degradation [4]. Recent studies have shown that these agriculture wastes have a pozzolanic property which contains high amorphous silica. It gives an opportunity for the construction industry to reduce their cost by reducing the amount of cement used, while preserving the environmental quality [5]. RHA obtained from different locations possess different chemical compositions. Abu Bakar reported that silica content in RHA varies in range of $85-95 \%[2]$.

The experiment to investigate the effect of MIRHA on the compressive strength of concrete was conducted at ages of 3, 7 and 28 days. Super plasticizer was used to increase the workability and MIRHA was used as a replacement of cement on a weight basis at 5, 10, 15 and $20 \%$ of cement content in concrete [6]. In addition to that, Sensale proved that the use of RHA in concrete leads to workability improvement, reduction of heat evolution and permeability as well as promoting good strength development of concrete [7].

Rame has investigated the utilization of RHA and Quarry Dust (QD) as partial cement replacement in self-compacting mortar (SCM) mixes [8]. The performance of SCM mixes has been observed at all ages and the rate of strength 
reduction decreased as the age progressed and it was concluded that the compressive strength of SCM will reduce with addition of the RHA at all ages.

An experimental study on cement mortar with replacement of 10, 15, 20, 25 and $30 \%$ of OPC with RHA was conducted by Muhammad et al. [9]. In their experimental work, RHA was obtained from an uncontrolled combustion process. It was concluded that the cement mortar with replacement of RHA at $20 \%$ has significantly improved the mortar strength, whilst 30\% replacement of cement with RHA showed increment in porosity of mortar at age of 28 days and 90 days as compared to OPC mortar.

\section{Methodology}

\subsection{Materials}

For this study the RHA was obtained from Padiberas National Berhad's (BERNAS) factory. The water-binder ratio was kept constant at 0.5 . Ordinary Portland Cement (OPC) type 1 and fine quarry sand was used as the fine aggregate where the sand passes sieve number $2.36 \mathrm{~mm}$.

In order to obtain the optimum MIRHA, the rice husks were burnt at a temperature of $400^{\circ} \mathrm{C}$ using an UTP Microwave Incinerator but in fact due to the incinerator condition the RHA were burnt at a temperature of $800^{\circ} \mathrm{C}$ as required [6]. This temperature will increase the silica content and the resulting ash has gray colour [1]. After the burning process, MIRHA was ground using abrasion mechine to increase its fineness. It was subjected to 3000 cycles to obtain the particles of optimum fineness and it took 1 hour and 30 minutes. The processed MIRHA was placed in air tight container to prevent any contamination. The preparation of the material is summarized in Figure 1.

\subsection{Mix design}

Trial and error method was adopted to determine the appropriate design proportion for the mortar used to produce the bricks. A total of 24 different mixtures were prepared. The replacement percentages of MIRHA are 5, 10, 15, 20 and 25\%. The binder-sand ratios are 1:3, 1:4, 1:5 and 1:6. Control mixtures without any replacement of MIRHA for the binder-sand ratios were also prepared and tested. In general for each binder-sand ratio, about 6 mixes were prepared including of the control samples as shown in Table 1.

\subsection{Laboratory testing}

Cube specimens of $100 \times 100 \times 100 \mathrm{~mm}$ were used to determine the compressive strength of MIRHA mortar. The compressive tests were carried out as per provisions of relevant codes (BS, ASTM and MS) at 7 and 28 days of curing using digital compressive testing machine. The compressive strength for each cube was recorded and the average values were determined. 


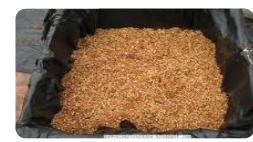

Rice husks obtained from rice milling
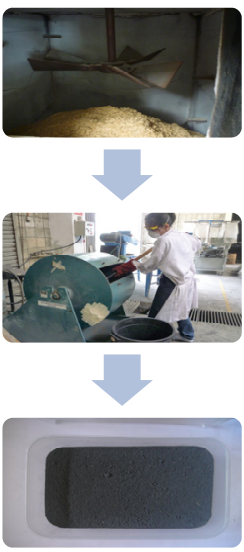

Rice husks burnt using UTP Microwave Incinerator at $400^{\circ} \mathrm{C}$
Grind MIRHA using Los Angeles Abrasion

Figure 1: Material preparation.

Table 1: $\quad$ Mortar mixes showing percentage of cement replaced by MIRHA.

\begin{tabular}{|c|c|c|c|c|c|c|}
\hline MIXTURE ID & CM & MIRHA5 & $\begin{array}{c}\text { MIRHA1 } \\
0\end{array}$ & $\begin{array}{c}\text { MIRHA } \\
15\end{array}$ & $\begin{array}{c}\text { MIRHA2 } \\
0\end{array}$ & $\begin{array}{c}\text { MIRHA2 } \\
5\end{array}$ \\
\hline $\begin{array}{c}\text { Percentage of } \\
\text { MIRHA }\end{array}$ & $0 \%$ & $5 \%$ & $10 \%$ & $15 \%$ & $20 \%$ & $25 \%$ \\
\hline
\end{tabular}

\section{Result and discussion}

\subsection{Compressive strength of normal mortar}

Compression test was carried out to determine the strength of cement mortar with different percentage of MIRHA in the mortar mixtures at different mixes ratio. Results of the tests obtained for mortar with 5, 10, 15, 20 and 25 percent of cement replaced by MIRHA were compared with control mix for each of the mixes $(1: 3,1: 4,1: 5$ and 1:6) as shown in Table 2.

The results are also presented in Figure 2 and Figure 3. It can be seen that, there is clear trend of decreasing compressive strength of mortar strength with decreasing cement content. On average, normal cement mortar has higher compressive strength than cement mortar incorporated with MIRHA. However, among that, cement mortar with $20 \%$ of MIRHA has shown higher results comparing to other MIRHA mixtures and at ratio of 1:6 the strength is seems slightly higher than the control mix. 
Table 2: Compression strength of cement mortar of different mix proportions and different percentage of MIRHA replacement.

\begin{tabular}{|c|c|c|c|c|}
\hline \multirow[t]{2}{*}{ Mixture Code } & \multirow[t]{2}{*}{ MIRHA (\%) } & \multirow{2}{*}{$\begin{array}{c}\text { Mix } \\
\text { Proportions }\end{array}$} & \multicolumn{2}{|c|}{$\begin{array}{l}\text { Compressive } \\
\text { strength (MPa) }\end{array}$} \\
\hline & & & 7 days & 28 days \\
\hline \multirow[t]{4}{*}{ Control mix (CM) } & 0 & $1: 3$ & 35.76 & 52.75 \\
\hline & & $1: 4$ & 21.31 & 29.34 \\
\hline & & $1: 5$ & 12.87 & 20.29 \\
\hline & & $1: 6$ & 11.34 & 12.64 \\
\hline \multirow[t]{4}{*}{ MIRHA5 } & 5 & $1: 3$ & 23.63 & 29.81 \\
\hline & & $1: 4$ & 3.07 & 4.75 \\
\hline & & 1:5 & 2.78 & 3.19 \\
\hline & & $1: 6$ & 2.38 & 3.32 \\
\hline \multirow[t]{4}{*}{ MIRHA10 } & 10 & $1: 3$ & 15.33 & 13.88 \\
\hline & & $1: 4$ & 9.37 & 8.77 \\
\hline & & $1: 5$ & 4.14 & 5.62 \\
\hline & & 1:6 & 3.46 & 3.99 \\
\hline \multirow[t]{4}{*}{ MIRHA15 } & 15 & $1: 3$ & 18.26 & 23.02 \\
\hline & & $1: 4$ & 12.65 & 15.58 \\
\hline & & $1: 5$ & 7.39 & 8.59 \\
\hline & & $1: 6$ & 5.94 & 6.80 \\
\hline \multirow[t]{4}{*}{ MIRHA20 } & 20 & $1: 3$ & 25.08 & 36.34 \\
\hline & & $1: 4$ & 10.58 & 18.29 \\
\hline & & $1: 5$ & 11.95 & 19.48 \\
\hline & & $1: 6$ & 12.06 & 20.24 \\
\hline \multirow[t]{4}{*}{ MIRHA25 } & 25 & $1: 3$ & 13.15 & 24.85 \\
\hline & & $1: 4$ & 7.81 & 15.27 \\
\hline & & $1: 5$ & 7.35 & 13.66 \\
\hline & & $1: 6$ & 4.32 & 8.21 \\
\hline
\end{tabular}

Compressive strength that was shown by cement mortar with $20 \%$ cement replacement of MIRHA indicated that MIRHA is pozzolanic materials gave 
higher compressive strength than $5 \%, 10 \%, 15 \%$, and $25 \%$ replacement of MIRHA in mortar. Although the strength is lower compared to controlled mortar but it has satisfied the minimum requirement for mortar compressive strength for some application such as bricks.

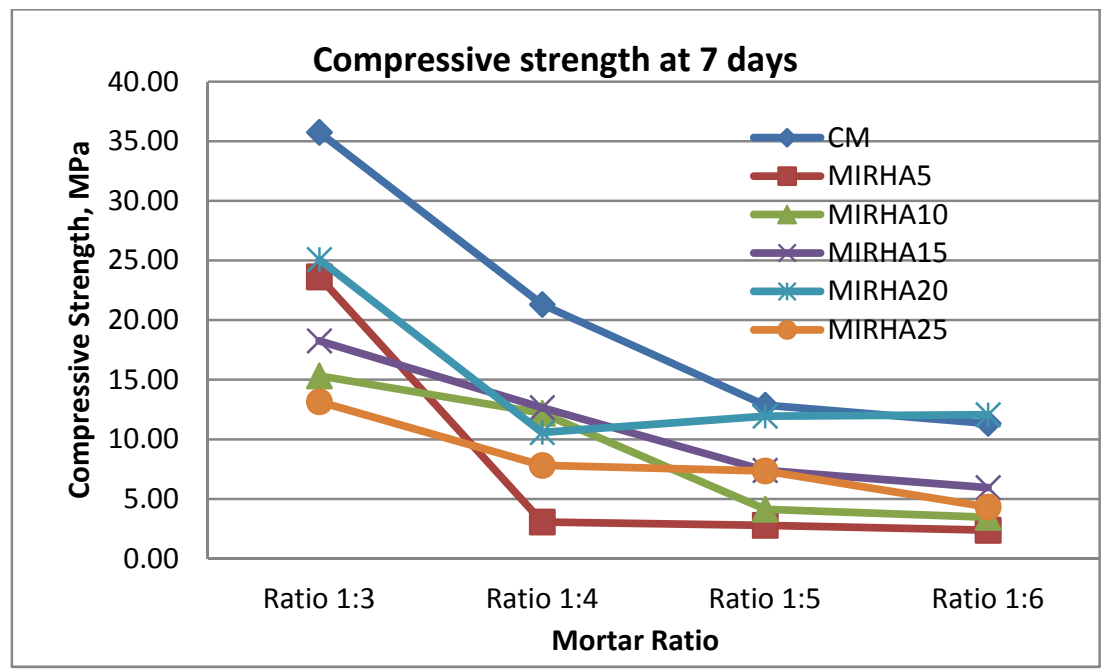

Figure 2: $\quad$ Compressive strength of cement mortar with MIRHA at 7 days.

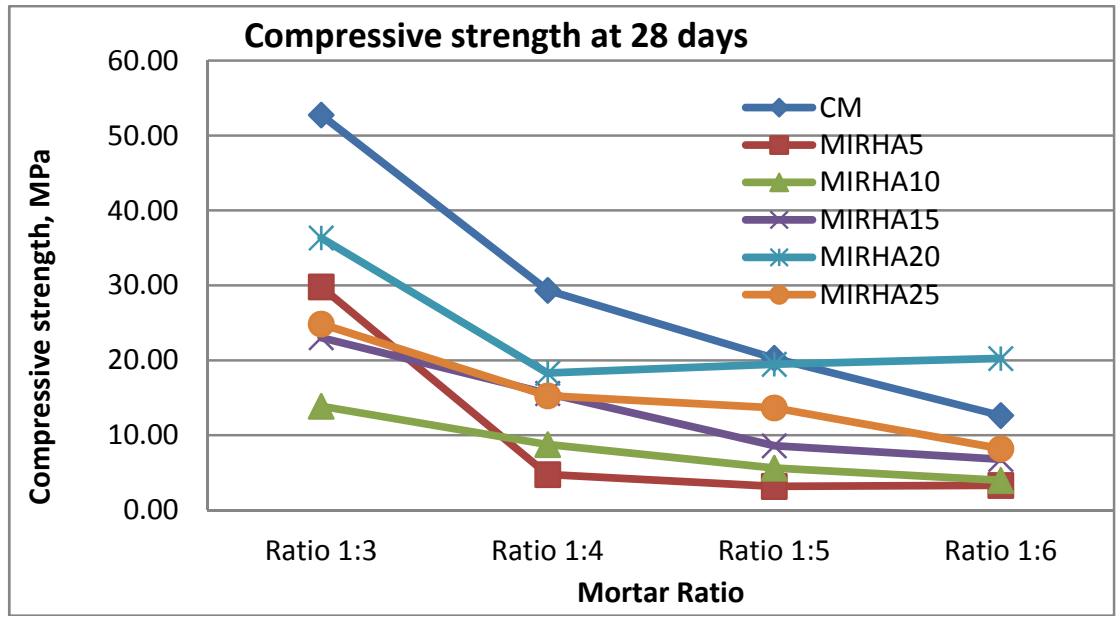

Figure 3: $\quad$ Compressive strength of cement mortar with MIRHA at 28 days.

\subsection{Application of MIRHA mix in brick mortar}

From the experimental work, it was observed that the compressive strength at ages of 7 days and 28 days of cement mortar incorporating $20 \%$ of MIRHA has 
shown good strength performances in terms achieving the least minimum compressive strength of brick. At ratio of 1:5 and 1:6, the compressive strength has also reached the minimum strength with less usage of cement.

The detailed summary of the mixtures meeting the requirements of brick for loading bearing wall and non-loading bearing wall in the British Standard, ASTM and Malaysian Standard are presented in Tables 2 and 3 respectively.

Table 3: $\quad$ Loading brick minimum requirement.

\begin{tabular}{|l|l|l|l|l|l|l|l|l|l|l|l|l|}
\hline Standard & \multicolumn{4}{|l|}{$\begin{array}{l}\text { British Standard } \\
\text { (7.0 Mpa) }\end{array}$} \\
\hline Ratio & $1: 3$ & $1: 4$ & $1: 5$ & $1: 6$ & $1: 3$ & $1: 4$ & $1: 5$ & $1: 6$ & $1: 3$ & $1: 4$ & $1: 5$ & $1: 6$ \\
\hline MIRHA5 & $\mathrm{V}$ & & & & $\mathrm{V}$ & & & & $\mathrm{V}$ & $\mathrm{V}$ & & \\
\hline MIRHA10 & $\mathrm{V}$ & $\mathrm{V}$ & & & $\mathrm{V}$ & $\mathrm{V}$ & & & $\mathrm{V}$ & $\mathrm{V}$ & $\mathrm{V}$ & $\mathrm{V}$ \\
\hline MIRHA15 & $\mathrm{V}$ & $\mathrm{V}$ & $\mathrm{V}$ & & $\mathrm{V}$ & $\mathrm{V}$ & $\mathrm{V}$ & & $\mathrm{V}$ & $\mathrm{V}$ & $\mathrm{V}$ & $\mathrm{V}$ \\
\hline MIRHA20 & $\mathrm{V}$ & $\mathrm{V}$ & $\mathrm{V}$ & $\mathrm{V}$ & $\mathrm{V}$ & $\mathrm{V}$ & $\mathrm{V}$ & $\mathrm{V}$ & $\mathrm{V}$ & $\mathrm{V}$ & $\mathrm{V}$ & $\mathrm{V}$ \\
\hline MIRHA25 & $\mathrm{V}$ & $\mathrm{V}$ & $\mathrm{V}$ & $\mathrm{V}$ & $\mathrm{V}$ & $\mathrm{V}$ & $\mathrm{V}$ & $\mathrm{V}$ & $\mathrm{V}$ & $\mathrm{V}$ & $\mathrm{V}$ & $\mathrm{V}$ \\
\hline
\end{tabular}

Table 4: $\quad$ Non-loading brick minimum requirement.

\begin{tabular}{|l|l|l|l|l|l|l|l|l|l|l|l|l|}
\hline Standard & \multicolumn{9}{|l}{$\begin{array}{l}\text { British Standard } \\
(2.0 \mathrm{MPa})\end{array}$} \\
\hline Ratio & $1: 3$ & $1: 4$ & $1: 5$ & $1: 6$ & $1: 3$ & $1: 4$ & $1: 5$ & $1: 6$ & $1: 3$ & $1: 4$ & \multicolumn{3}{l|}{$\begin{array}{l}\text { MSTM } \\
\text { (3.5 MPa) }\end{array}$} & $1: 6$ \\
\hline MIRHA5 & $\mathrm{V}$ & $\mathrm{V}$ & $\mathrm{V}$ & $\mathrm{V}$ & $\mathrm{V}$ & $\mathrm{V}$ & & & $\mathrm{V}$ & $\mathrm{V}$ & $\mathrm{V}$ & $\mathrm{V}$ \\
\hline MIRHA10 & $\mathrm{V}$ & $\mathrm{V}$ & $\mathrm{V}$ & $\mathrm{V}$ & $\mathrm{V}$ & $\mathrm{V}$ & $\mathrm{V}$ & $\mathrm{V}$ & $\mathrm{V}$ & $\mathrm{V}$ & $\mathrm{V}$ & $\mathrm{V}$ \\
\hline MIRHA15 & $\mathrm{V}$ & $\mathrm{V}$ & $\mathrm{V}$ & $\mathrm{V}$ & $\mathrm{V}$ & $\mathrm{V}$ & $\mathrm{V}$ & $\mathrm{V}$ & $\mathrm{V}$ & $\mathrm{V}$ & $\mathrm{V}$ & $\mathrm{V}$ \\
\hline MIRHA20 & $\mathrm{V}$ & $\mathrm{V}$ & $\mathrm{V}$ & $\mathrm{V}$ & $\mathrm{V}$ & $\mathrm{V}$ & $\mathrm{V}$ & $\mathrm{V}$ & $\mathrm{V}$ & $\mathrm{V}$ & $\mathrm{V}$ & $\mathrm{V}$ \\
\hline MIRHA25 & $\mathrm{V}$ & $\mathrm{V}$ & $\mathrm{V}$ & $\mathrm{V}$ & $\mathrm{V}$ & $\mathrm{V}$ & $\mathrm{V}$ & $\mathrm{V}$ & $\mathrm{V}$ & $\mathrm{V}$ & $\mathrm{V}$ & $\mathrm{V}$ \\
\hline
\end{tabular}

\subsection{Environmental implication}

Most of the vertical walls in Malaysia are made from bricks especially in residential premises. Thus, by using the bricks made from mortar with MIRHA, it able to reduce the amount of the used cement at least $20-25 \%$ in total.

For the non-structural wall, the replacement could extend to more than $25 \%$ which inherently will further reduce the amount of cement used. Most walls in Malaysia are acting as partition walls only. Further investigations are required to determine the exact mix proportion that could be adopted. This preliminary research intended to investigate the potential of MIRHA application in brick industry.

\section{Conclusion}

The following conclusions could be drawn from the study:

- The MIRHA has shown potential as a cement replacement material in cement mortar from the experimental results and able to reduce the 
amount of cement used in construction sector especially in brick production and promote to be environmental friendly construction product.

- Bricks with the binder sand ratio of 1:6 with 20\% MIRHA meets the minimum requirement of three (3) brick standard; ASTM, BS and MS, essentially used least amount of cement.

\section{Acknowledgement}

We would like to thank the Universiti Teknologi PETRONAS for providing facilities and funding to accomplish this research.

\section{References}

[1] Kusbiantoro A. (2008). The Effect of Microwave Incinerated Rice Husk Ash (MIRHA) on concrete properties, Msc Thesis, Universiti Teknologi PETRONAS.

[2] Abu Bakar B.H., Ramadhansyah Putrajaya C and Hamidi Abdulaziz (2010). Malaysia Rice Husk Ash- Improving the durability and corrosion resistance of concrete:Pre-review. Concrete Research Letter, Vol 1(1).

[3] Nuruddin, M.F and Darmawan, M.S., (2010). Compressive Strength and Microstructure Properties of Polymeric Concrete Incorporating Pulverized Fuel Ash (PFA) and Microwave Incinerated Rice Husk Ash (MIRHA). In: Proceedings of International Seminar on Applied Technology, Science, and Arts (2nd APTECS), 21-22 Dec. 2010, Surabaya, Indonesia.

[4] Hwang C.L. and Chandra S., (1996).The Use of Rice Husk Ash in Concrete. In S. Chandra, Waste Materials Used in Concrete Manufacturing. William Andrew Pub, pp 184-234.

[5] Ajiwe V.I.E., Okeke C.A., and Akigwe F.C., (2000).A Preliminary Study of Manufacture of Cement from Rice Husk Ash, .Bio resource Technology 73, pp 37-39.

[6] Kamal N. M., (2008). The Influence of Burning Temperatures and Percentage Inclusion of Microwave Incinerated Rice Husk Ash (MIRHA) on normal strength concrete. ICCBT, pp 531-538.

[7] Sensale G. (2006). Strength Development of Concrete with Rice Husk. Cement \& Concrete Composites, 159-160.

[8] Rame M. et al. (2010). Development and study of the strength of selfcompacting mortar mixes using local materials. Journals of Materials in Civil Engineering.

[9] Muhammad H.R., Keramat A.M. and Tarif U.A., (2010). Mortar Incorporating Rice Husk Ash: Strength and Porosity. European Journal of Scientific Research. Vol 40 No.3, pp 471-477. 